\title{
Human and animal fasciolosis: Coprological survey in Narok, Baringo and Kisumu counties, Kenya
}

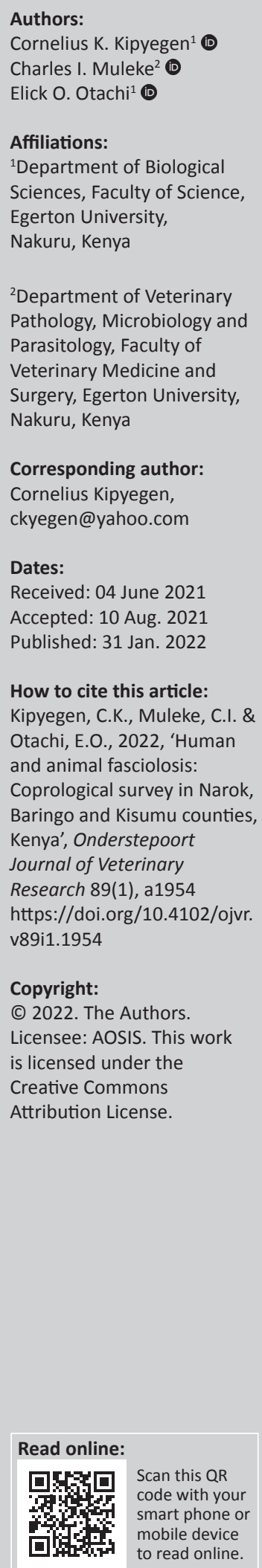

Fasciolosis is caused by digenean trematodes of the genus Fasciola. The principal definitive hosts are cattle, sheep and goats. Humans are infected as accidental hosts. Fasciolosis is one of the major neglected tropical diseases and is considered an emerging zoonotic infection. This study was aimed at determining the prevalence of human and domestic animal fasciolosis in selected counties in Kenya. Stool samples for Fasciola diagnosis were collected from humans and domestic animals and transported to the laboratory at Egerton University and processed using sedimentation technique and examined for the presence of eggs. A total of 272 human samples collected were all negative for Fasciola eggs. A total of 582 domestic animals (cattle [46.0\%], sheep [29.9\%] and goats [24.1\%]) samples collected had overall prevalence of $30.9 \%$ for Fasciola infection. There was no significant differences $(p>0.05)$ between the prevalence of fasciolosis and origin of the animals, sex and season. There was a significant difference $(p<0.05)$ between the prevalence of fasciolosis and domestic animals, age and body condition. The prevalence of fasciolosis was high in two irrigation schemes which favour the breeding of intermediate host snail and grazing of animals along the irrigation canals where metacercaria of Fasciola parasites could be present on the vegetation. Although human fasciolosis was not detected in this study, the presence of animal fasciolosis can pose public health risk because of its zoonotic nature. Therefore, it is important to introduce measures which would help to reduce the exposure of animals to Fasciola infection.

Keywords: fasciolosis; prevalence; human; domestic animals; zoonosis; Kenya.

\section{Introduction}

Fasciolosis is a disease caused by digenean trematodes of the genus Fasciola (Meerkhan, Razak \& Younis 2013). There are two species causing infection, Fasciola hepatica and Fasciola gigantica (Avcioglu et al. 2014). Fasciola hepatica has a worldwide distribution but predominates in temperate zones while F. gigantica is found primarily in tropical regions (Abebe et al. 2010), but the two parasites overlap in subtropical regions (Khanjari et al. 2014). The primary definitive hosts of Fasciola parasites are the domestic ruminants (Khanjari et al. 2014), while humans become accidentally infected (Nguyen et al. 2018). Fasciolosis has been identified as a neglected tropical disease where over 180 million people in 75 countries are at risk of being infected (Liu et al. 2014; Maciel et al. 2018). Globally, over 600 million animals are at risk of getting infected with Fasciola parasites (Maciel et al. 2018; Rehman et al. 2016). Fasciolosis causes massive economic burden in the livestock enterprise as a result of decreased animal productivity, characterised by reduced growth rate, low quality meat and milk, infertility and diseases (Rehman et al. 2016; Shahzad et al. 2012). Prevalence of $30 \%-90 \%$ of Fasciola infection in ruminants has been documented in Africa region (Alemneh \& Ayelign 2017).

The domestic ruminants and humans get infected by ingesting of water, food and watercress or vegetation contaminated with metacercariae infective stages of Fasciola parasite (Mas-Coma, Valero \& Bargues 2009). The biology of the parasite depends on the presence of freshwater snail intermediate hosts of family Lymnaeidae (Khanjari et al. 2014).

The snail intermediate hosts involved in the transmission of F. gigantica and F. hepatica are Lymnaea natalensis and Lymnaea truncatula, respectively (Legesse et al. 2017). The presence of suitable environmental conditions including temperature, rainfall and soil moisture influences the breeding and development of the snail intermediate hosts of Fasciola species (Khanjari et al. 2014). In addition, fasciolosis transmission can be influenced by climatic factors (Relf et al. 2011). The 
areas conducive for the breeding of the intermediate snail host include flooded pastures, grazing areas along lakeshores, slow flowing streams and river banks.

The diagnosis of fasciolosis in animals relies on the parasitological examination of ova of Fasciola in the faecal sample (Shahzad et al. 2012). Coprological analysis is crucial because it provides important information that helps to identify the number of infected animals releasing Fasciola eggs resulting in the contamination of the environment (Kleiman et al. 2005). No other diagnostic methods can provide the valuable information that coprological methods give. Thus, these are very important for epidemiological surveys.

In Kenya, there is no documented data on human fasciolosis, and the data on domestic animal fasciolosis is limited (Kanyari, Kagira \& Mhoma 2009; Kithuka et al. 2002; Mungube et al. 2012). This study aimed to investigate the prevalence of fasciolosis in humans and domestic animals in Narok, Baringo and Kisumu Counties.

\section{Materials and methods}

\section{Study area}

This study was carried out in Mara river basin in Narok County, Perkera irrigation scheme in Baringo County and Ahero irrigation scheme in Kisumu County, Kenya (Figure 1). The residents of the study area practise irrigation and livestock farming for both beef and milk production. Perkera irrigation scheme covers a total area of $2350 \mathrm{ha}$. The rainfall varies from $1000 \mathrm{~mm}$ to $1500 \mathrm{~mm}$ in the highlands to $600 \mathrm{~mm}$ per annum in the lowlands. The temperatures vary between $25^{\circ} \mathrm{C}$ and $30^{\circ} \mathrm{C}$; however in January the temperatures rises up to $35^{\circ} \mathrm{C}$ on average. The Ahero irrigation scheme has an area of $2085.9 \mathrm{~km}^{2}$ and annual relief rainfall between $1200 \mathrm{~mm}$ and $1300 \mathrm{~mm}$ with a mean annual temperature of $23^{\circ} \mathrm{C}$ with a range of between $20^{\circ} \mathrm{C}$ and $35^{\circ} \mathrm{C}$. The $13750 \mathrm{~km}^{2}$ drainage area of the Mara River basin covers the agricultural and forested areas in the upper basin, the open pastureland in the middle portion of the basin and the Masai Mara Game Reserve in Kenya $\left(1718 \mathrm{~km}^{2}\right.$, all of which is within the Mara River Basin). The rainfall is bimodal and the highest annual rainfall amount is received in the high altitude areas with $1100 \mathrm{~mm}$ on the average.

\section{Sample collection}

\section{Stool sample collection in humans}

Human stool samples were collected from Ahero Subcounty Hospital and Marigat Sub-county Hospital from January 2016 to March 2017. The participants were informed about the study and consent was obtained before inclusion in the study. A total of 272 human stool samples were collected and microscopically examined in this study. The participants were issued with clean wide-mouth polypots to collect about $10 \mathrm{~g}$ of stool specimen in health facility and preserved in 10\% formalin solution and stored at $4{ }^{\circ} \mathrm{C}-8{ }^{\circ} \mathrm{C}$ in cool box and transported to the laboratory for processing.

\section{Stool sample collection from animals}

Structured questionnaires were administered to the livestock farmers to get information on the age, sex and species of the domestic animals. A maximum of five of each of cattle, sheep and goats per herdsman were sampled. In this study, faecal samples were collected and examined from a total of 582 animals. Faecal samples were obtained directly from the rectum in disposable plastic gloves or from the ground if it was seen being dropped by the animal. The glove was turned inside out, carefully tied, labelled and transported in a cool box to the laboratory where it was processed using sedimentation technique.

\section{Faecal examination by sedimentation technique}

The sedimentation technique was used to find out the presence of Fasciola species eggs (Usip et al. 2014). Approximately $3 \mathrm{~g}$ of faeces was mixed with $1 \mathrm{~L}$ of water and $8.5 \mathrm{~g}$ of salt and passed through $80 \mu \mathrm{m}$-mesh sieve. The sieve and glass were washed at each stage. The filtrates were placed in centrifuge conical tube and centrifuged for $10 \mathrm{~min}$ at 5000 revolutions per minute (rpm). The supernatant was discarded. A small quantity of the sediment left at the bottom was scooped with spatula and placed on a clean slide. The prepared slide was examined under the light microscope using $\times 10$ objective of the microscope. One drop of $1 \%$ methylene blue was added to the preparation to make the eggs more visible.

\section{Data analysis}

Data that was collected from structured questionnaires and faecal examination was entered into a Microsoft Excel spreadsheet, thoroughly checked for errors and properly coded before subjecting to statistical analysis. The data was imported from the Microsoft Excel and analysed using Statistical Package for the Social Sciences (SPSS) version 26.0 statistical software. Descriptive statistics were used to quantify the prevalence of Fasciola species infection. The total prevalence was calculated by dividing the number of Fasciola infected animals by the total number of animals examined and then multiplied by 100 .

Total prevalence $=\frac{\text { Total number of infected animals }}{\text { Total number of animals examined }} \times 100$ [Eqn1]

Categorical data was analysed using univariable logistic regression analysis to determine the association of the risk factors with infection, including age, sex, species, season, and origin. A 5\% significance level was used to determine where there was significant differences in the parameters.

\section{Ethical considerations}

This study was approved by the Egerton University Research and Ethical Committee (EU/RE/DVC/009) and the Kenya 


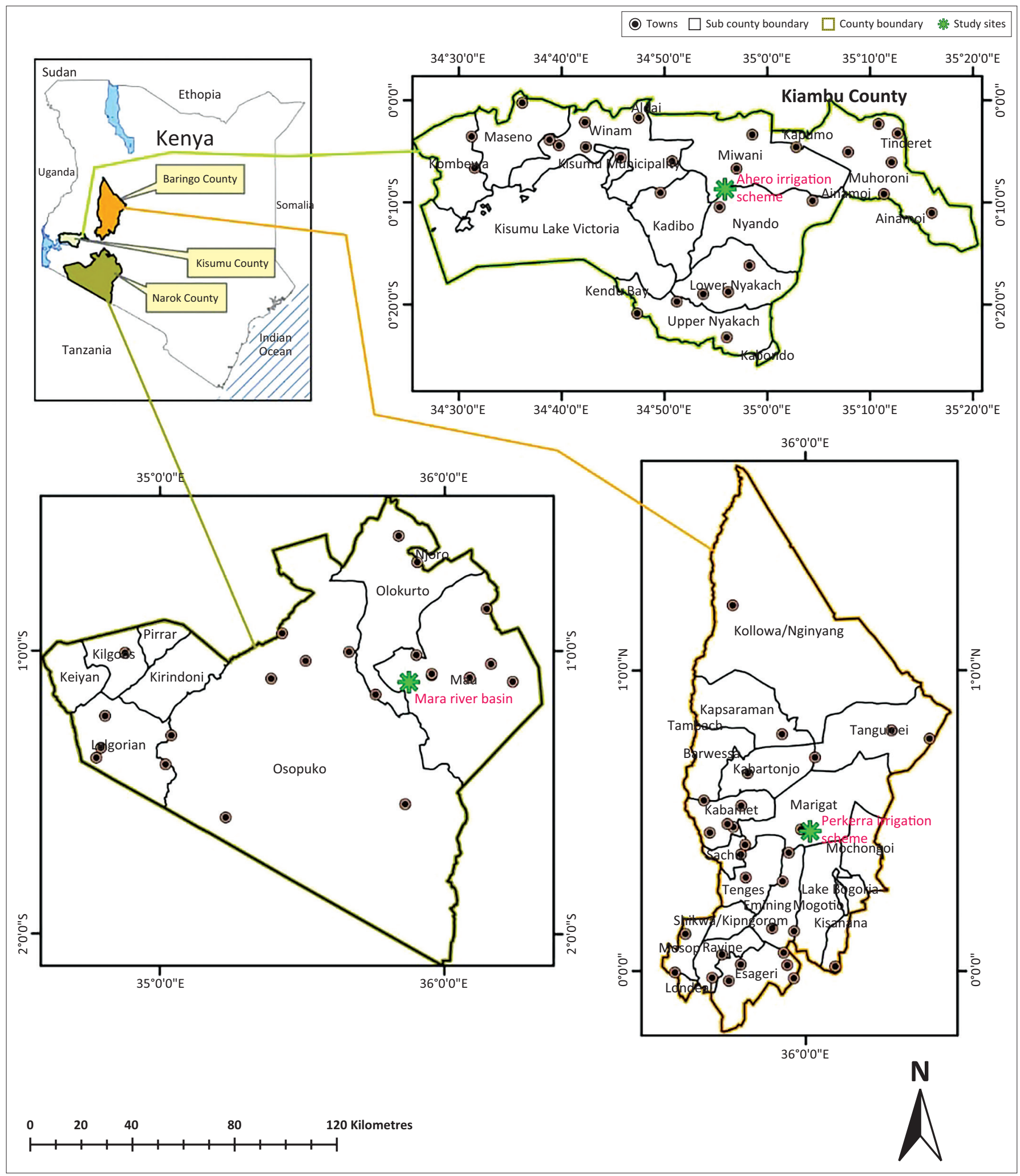

Source: Commission on Revenue Allocation (CRA), 2013, Kenya: County fact sheet, 2nd edn., CRA, Nairobi.

Note: The study sites represented by green asterisk.

FIGURE 1: Map of Kenya showing the location of Narok, Ahero and Baringo Counties, where the samples were collected.

National Commission for Science, Technology and Innovation (NACOSTI/P/15/8095/6943). The authors assert that all procedures contributing to this work comply with the ethical standards of the relevant national and institutional committees on human experimentation and with the Helsinki Declaration 1975, as revised in 2008 (EU/RE/DVC/009).

\section{Results}

In this study, the human stool samples that were collected and processed using sedimentation method were all negative for Fasciola parasite eggs. The overall animal prevalence of Fasciola parasites in the three study areas was 30.9\% (Table 1). 
TABLE 1: Overall prevalence and infection status of fasciolosis with different variables.

\begin{tabular}{|c|c|c|c|c|c|c|c|}
\hline \multirow[t]{3}{*}{ Variable } & \multirow[t]{3}{*}{ Category } & \multicolumn{6}{|c|}{ Infection status } \\
\hline & & \multicolumn{2}{|c|}{ Non-infected } & \multicolumn{2}{|c|}{ Infected } & \multicolumn{2}{|c|}{ Total } \\
\hline & & $n$ & $\%$ & $n$ & $\%$ & $n$ & $\%$ \\
\hline \multirow[t]{3}{*}{ Origin } & Perkera & 149 & 25.6 & 72 & 12.4 & 221 & 38.0 \\
\hline & Ahero & 129 & 22.2 & 75 & 12.9 & 204 & 35.1 \\
\hline & Narok & 124 & 21.3 & 33 & 5.7 & 157 & 27.0 \\
\hline Total & & 402 & 69.1 & 180 & 30.9 & 582 & 100.0 \\
\hline \multirow{3}{*}{$\begin{array}{l}\text { Domestic } \\
\text { animal }\end{array}$} & Cattle & 178 & 30.6 & 90 & 15.5 & 268 & 46.0 \\
\hline & Goat & 112 & 19.2 & 28 & 4.8 & 140 & 24.1 \\
\hline & Sheep & 112 & 19.2 & 62 & 10.7 & 174 & 29.9 \\
\hline Total & & 402 & 69.1 & 180 & 30.9 & 582 & 100.0 \\
\hline \multirow[t]{2}{*}{ Sex } & Male & 154 & 26.5 & 68 & 11.7 & 222 & 38.1 \\
\hline & Female & 248 & 42.6 & 112 & 19.2 & 360 & 61.9 \\
\hline Total & & 402 & 69.1 & 180 & 30.9 & 582 & 100.0 \\
\hline \multirow[t]{3}{*}{ Age } & $<1$ year & 31 & 5.3 & 52 & 8.9 & 83 & 14.3 \\
\hline & $1-4$ years & 291 & 50.0 & 88 & 15.1 & 379 & 65.1 \\
\hline & $>5$ years & 80 & 13.7 & 40 & 6.9 & 120 & 20.6 \\
\hline Total & & 402 & 69.1 & 180 & 30.9 & 582 & 100.0 \\
\hline \multirow{3}{*}{$\begin{array}{l}\text { Body } \\
\text { condition }\end{array}$} & Poor & 64 & 11.0 & 95 & 16.3 & 159 & 27.3 \\
\hline & Medium & 175 & 30.1 & 59 & 10.1 & 234 & 40.2 \\
\hline & Good & 163 & 28.0 & 26 & 4.5 & 189 & 32.5 \\
\hline Total & & 402 & 69.1 & 180 & 30.9 & 582 & 100.0 \\
\hline \multirow[t]{2}{*}{ Season } & Dry season & 163 & 28.0 & 52 & 8.9 & 215 & 36.9 \\
\hline & Wet season & 239 & 41.1 & 128 & 22.0 & 367 & 63.1 \\
\hline Total & & 402 & 69.1 & 180 & 30.9 & 582 & 100.0 \\
\hline
\end{tabular}

A total of 582 animal faecal samples of cattle (46.0\%), sheep (29.9\%) and goats (24.1\%) were examined in this study.

Fasciola infection was almost similar in Perkera (12.4\%) and Ahero (12.9\%) irrigation schemes as compared to the infection in Narok (5.7\%). The general Fasciola infection among cattle, sheep and goats were $15.5 \%, 10.7 \%$, and $4.8 \%$, respectively.

According to each study area, the prevalence of Fasciola parasite infection was found to be Perkera (32.6\%), Ahero $(36.8 \%)$ and Narok $(21.0 \%)$. The prevalence of fasciolosis was not significantly different for the origin of the animals $(p>0.05)$ (Table 2). However, the risk of Fasciola infection was found to be high in the animals from Perkera and Ahero compared to the animals from Narok. The animals from Perkera and Ahero were almost twice (odds ratio [OR] = 1.771 and $\mathrm{OR}=1.846$ ) more likely to be infected with Fasciola parasites than in Narok.

The results obtained show that the prevalence of Fasciola was significantly different between the species of the domestic animals. The prevalence was high in sheep (35.6\%), followed by cattle (33.6\%) and goats (20.0\%). The difference of Fasciola prevalence in relation to animal sex was not statistically significant, although female animals had higher infection than in male animals. Evaluating the relationship between prevalence and age, it was found that the prevalence of Fasciola was significantly different. The prevalence was higher in the animals of less than 1 year old at $62.7 \%$ and significantly lower in those which were between 1 and 4 years old at $23.2 \%$. The risk of infection in the animals of less
TABLE 2: Univariate logistic regression analysis of fasciolosis with associated risk factors.

\begin{tabular}{|c|c|c|c|c|c|c|c|}
\hline \multirow[t]{2}{*}{ Variable } & \multirow[t]{2}{*}{ Category } & \multirow{2}{*}{$\begin{array}{c}\text { Total } \\
\text { examined }\end{array}$} & \multicolumn{2}{|c|}{ Total infected } & \multirow[t]{2}{*}{ OR } & \multirow[t]{2}{*}{$\mathrm{Cl} 95 \%$} & \multirow[t]{2}{*}{$p$} \\
\hline & & & $n$ & $\%$ & & & \\
\hline \multirow[t]{4}{*}{ Origin } & & & & & & & 0.074 \\
\hline & Perkera & 221 & 72 & 32.6 & 1.771 & $1.004-3.124$ & 0.048 \\
\hline & Ahero & 204 & 75 & 36.8 & 1.846 & $1.045-1.045$ & 0.035 \\
\hline & Narok & 157 & 33 & 21.0 & - & & - \\
\hline \multirow{4}{*}{$\begin{array}{l}\text { Domestic } \\
\text { animal }\end{array}$} & & & & & & & 0.002 \\
\hline & Cattle & 268 & 90 & 33.6 & 1.231 & $0.741-2.045$ & 0.423 \\
\hline & Goat & 140 & 28 & 20.0 & 0.393 & $0.207-0.749$ & 0.004 \\
\hline & Sheep & 174 & 62 & 35.6 & - & & - \\
\hline \multirow[t]{2}{*}{ Sex } & Male & 222 & 68 & 30.6 & 0.854 & $0.550-1.325$ & 0.482 \\
\hline & Female & 360 & 112 & 31.1 & - & & - \\
\hline \multirow[t]{4}{*}{ Age } & & & & & & & 0.000 \\
\hline & $<1$ year & 83 & 52 & 62.7 & 21.736 & $9.481-49.831$ & 0.000 \\
\hline & $1-4$ years & 379 & 88 & 23.2 & 2.660 & $1.426-4.963$ & 0.002 \\
\hline & $>5$ years & 120 & 40 & 33.3 & - & & - \\
\hline \multirow{4}{*}{$\begin{array}{l}\text { Body } \\
\text { condition }\end{array}$} & & & & & & & 0.000 \\
\hline & Poor & 159 & 95 & 59.7 & 20.631 & $10.612-40.107$ & 0.000 \\
\hline & Medium & 234 & 59 & 25.2 & 2.496 & $1.419-4.389$ & 0.001 \\
\hline & Good & 189 & 26 & 13.8 & - & & - \\
\hline \multirow[t]{2}{*}{ Season } & Dry season & 215 & 52 & 24.2 & 0.675 & $0.427-0.427$ & 0.094 \\
\hline & Wet season & 367 & 128 & 34.9 & - & & - \\
\hline
\end{tabular}

$\mathrm{OR}$, odds ratio; $\mathrm{Cl}$, confidence interval.

than 1 year old was found to be 22 times $(\mathrm{OR}=21.736)$ more than those above 5 years old.

Fasciola prevalence was significantly different in relation to body condition; the prevalence was higher in the animals with poor body condition (59.7\%). The animals with poor body condition were almost 21 times $(\mathrm{OR}=20.631)$ more likely to be infected with Fasciola parasites than those with good body condition. The difference between the prevalence of Fasciola infection and season was not significant, but there was high prevalence during wet season (34.9\%) than dry season $(24.2 \%)$.

\section{Discussion}

The stool samples collected from humans were all negative for Fasciola eggs. This shows that the prevalence of animal fasciolosis is not predictive of the prevalence of human Fasciola infection in endemic regions (Mas-Coma 2004; Tolan 2011). Although coprological examination is the standard diagnosis method at clinical level (Rinaldi et al. 2012), the negative results from human faecal examination could be attributed to the shortcoming of the coprological examination which has low sensitivity because Fasciola takes about 10-14 weeks to release eggs (Rabia, Sabry \& Nagy 2010; Rehman et al. 2016). In addition, Fasciola eggs are not found in the faeces because of intermittent shedding of eggs by the adult flukes in the liver (Shazad et al. 2012), presence of Fasciola parasites in low numbers (Rehman et al. 2016), or the flukes are still undergoing maturation (Rabia et al. 2010). To overcome the limitation of faecal examination, sensitive diagnostic methods like enzyme-linked immunosorbent assays (ELISA) can be used to test for the presence of antibodies against Fasciola in serum (Rehman et al. 2016), and Fasciola antigens faeces (Tolan 2011). Molecular techniques 
like polymaerase chain reaction (PCR) have also been developed which are highly specific and have been utilised in the diagnosis and differentiating the species of Fasciola parasites in faecal samples (Shazad et al. 2012).

The overall prevalence of Fasciola infection in the three study areas was $30.9 \%$. These results are in agreement that fasciolosis is considered the most important infection in tropical regions with a prevalence of $30 \%-90 \%$ in Africa (Alemneh \& Ayelign 2017), and 34\% prevalence of fasciolosis reported in central Kenya (Waruiru et al. 2000). The prevalence of fasciolosis reported in other regions of the world shows that in America, sheep (8.87\% - 100.00\%) and goat $(24.50 \%-100.00 \%)$, Asia, cattle $(0.71 \%-69.20 \%)$ and goat $(0.00 \%-47.00 \%)$, in Africa sheep $(0.19 \%-73.70 \%)$, goat $(0.28 \%-58.40 \%)$ and cattle $(1.20 \%-91.00 \%)$ and in Pakistan, sheep $(14.67 \%-39.20 \%)$, goat $(4.08 \%-28.75 \%)$ and cattle (25.46\%) (Khademvatan et al. 2019).

In this study, slightly high prevalence of fasciolosis was recorded in Ahero and Perkera compared to Narok. There was no statistically significant difference $(p>0.05)$ between the prevalence of fasciolosis and the origin of the animals. The variation in the prevalence of fasciolosis in the study sites probably associated with the presence of different environmental conditions (rainfall, water logged marshy areas) and difference in climato-ecological conditions which favours the existence and development of intermediate host snails and parasite (Alemneh \& Ayelign 2017; Aragaw \& Tilahun 2019; Belete 2017; Khanjari et al. 2014). The high prevalence in Perkera and Ahero irrigation schemes compared to Narok, could be attributed to the irrigation activities taking place favouring the breeding of intermediate host snails. The animals from Perkera and Ahero were almost two times $(\mathrm{OR}=1.771$ and $\mathrm{OR}=1.846)$ more likely to be infected with Fasciola parasites than in Narok.

The prevalence of fasciolosis was significantly different in relation to the species of the domestic animals. Higher prevalence was recorded in sheep, whereas goats had lower prevalence. This is in line with the results obtained from Iran (Khanjari et al. 2014). The results are also almost similar to the reports from the studies conducted in Kenya, where in Taveta, cattle, goats, sheep had prevalence of 25.9\%, 23.4\%, $33.3 \%$, respectively (Mungube et al. 2012). Also, in Nyanza region, sheep and goats had prevalence of $(37 \%)(36 \%)$, respectively, (Kanyari et al. 2009). The high prevalence of Fasciola infection in sheep may be attributed to their grazing habits mostly on vegetation on the ground where metacercaria are mostly found which increases their susceptibility compared to goats and cattle (Theodoropoulos 2011). In this study, the high prevalence of fasciolosis in cattle could be because Fasciola parasites have adapted well to bovine species (Khademvatan et al. 2019).

The difference of Fasciola prevalence in relation to animal sex was not statistically significant, although female animals had slightly higher Fasciola infection than in male animals. This is in agreement with the reports from other studies
(Legesse et al. 2017; Solomon \& Abebe 2007). The high prevalence of parasitism in females is attributed to pregnancy and peri-parturient period that lead to stress and reduced immune status (Khan et al. 2010). In this study, the animals (cattle, sheep and goats) examined were not separated during grazing. Therefore, both male and female domestic animals had equal exposures to contaminated grass (Tilahun et al. 2014).

Fasciola prevalence in relation to age was significantly different, where animals of one year old and below recorded higher prevalence and animals between one and four years old had significantly lower prevalence. This is in line with the reports from Ethiopia (Asmare \& Samuel 2015; Solomon \& Abebe 2007). The animals which are less than one year old were almost 22 times $(\mathrm{OR}=21.736)$ more likely to be infected with Fasciola parasites than those above five years old. The high prevalence rate of fasciolosis in young animals can be as a result of undeveloped immunity compared to the adult animals which have developed a certain level of immunity because of repeated exposure to Fasciola infection (Belete 2017).

Fasciola prevalence was significantly higher in animals with poor body condition. This finding agrees with the results obtained from another study (Belete 2017). The animals which had poor body condition were almost 21 times $(\mathrm{OR}=$ 20.631) more likely to be infected with Fasciola parasites than those animals with good body condition. Animals with poor body condition have less resistance to infections and are therefore more susceptible to parasitic diseases compared to healthy animals.

The variation in the prevalence of Fasciola infection in relation to season was not significantly different, although there was high prevalence during wet season than dry season. This could be as a result of irrigation activities taking place especially in Perkera and Ahero irrigation schemes. In these areas, there is constant water for farming in the irrigation canals and also paddy fields which provide favourable breeding sites for the intermediate host snail. In areas that depend on rainfall, seasonality of fasciolosis is closely linked to the effects of rainfall and temperature, which may directly affect both intermediate hosts and the parasite (Aleixo et al. 2015). The difference in management system can contribute to the difference in the prevalence of fasciolosis regardless of the season (Legesse et al. 2017).

\section{Conclusion}

The prevalence of fasciolosis was high in two study areas, namely, Ahero and Perkera irrigation schemes. This is as a result of the presence of marshy areas favouring the breeding of intermediate host snail and also grazing of animals along the irrigation canals and paddy fields where metacercariae of Fasciola parasites could be present on the vegetation. Although there was no human fasciolosis, it can pose public health risk to the residents in those areas because fasciolosis is zoonotic. Therefore, it is important to introduce measures which would 
assist to reduce the exposure of animals to the liver flukes, such as grazing animals away from high-risk areas, and strategic use of anthelmintics eective against liver fluke infections. In addition, an integrated approach with a combination of public health education, chemotherapy and intermediate host control could help in controlling the spread of fasciolosis.

\section{Acknowledgements Competing interests}

The authors declare that they have no financial or personal relationships that may have inappropriately influenced them in writing this article.

\section{Authors' contributions}

C.K.K. designed the project, acquired and analysed data and wrote the manuscript. C.I.M. and E.O.O. supervised the research, contributed to writing and reviewing of the manuscript.

\section{Funding information}

This work was supported by the Kenya National Commission for Science, Technology and Innovation (NACOSTI) (grant number NACOSTI/RCD/ST\&I/7TH CALL/PhD/168).

\section{Data availability}

Data sharing is not applicable to this article as no new data were created in this study.

\section{Disclaimer}

The views and opinions expressed in this article are those of the authors and do not necessarily reflect the official policy or position of any affiliated agency of the authors.

\section{References}

Abebe, R., Abunna, F., Berhane, M., Mekuria, S., Megersa, B. \& Regassa, A., 2010, 'Fasciolosis: Prevalence, financial losses due to liver condemnation and evaluation of a simple sedimentation diagnostic technique in cattle slaughtered at Hawassa Municipal Abattoir, Southern Ethiopia', Ethiopian Veterinary Journal 14(1), 39-51.

Aleixo, M.A., Freitas, D.F., Dutra, L.H., Malone, J., Martins, I.V.F. \& Marcelo, B.M., 2015, 'Fasciola hepatica: Epidemiology, perspectives in the diagnostic and the use of geoprocessing systems for prevalence studies', Semina: Ciências Agrárias 36(3), 1451-1466. https://doi.org/10.5433/1679-0359.2015v36n3p1451

Alemneh, T. \& Ayelign, M., 2017, 'Study on prevalence and economic importance of bovine fasciolosis in three districts of North-East Amhara Region, Ethiopia', Journal of Infectious \& Non Infectious Diseases 3, 024

Aragaw, K. \& Tilahun, H., 2019, 'Coprological study of trematode infections and associated host risk factors in cattle during the dry season in and around Bahi Dar, Northwest Ethiopia', Veterinary and Animal Science 7, 100041. https://doi. org/10.1016/j.vas.2018.11.002

Asmare, G. \& Samuel, D., 2015, 'Prevalence of bovine fasciolosis and its associated risk factor in and around Dangila District, Awi Administration Zone, Northwestern Ethiopia', European Journal of Biological Sciences 7(3), 114-119.

Avcioglu, H., Guven, E., Balkaya, I., Kaynar, O. \& Hayirli, A., 2014, 'Evaluation of coprological and serological techniques for diagnosis of bovine fasciolosis', Israel Journal of Veterinary Medicine 69(4), 203-210.

Belete, K., 2017, 'A cross sectional study on the coprological prevalence of ovine fasciolosis in Amhara Sayint District, Ethiopia', Journal of Veterinary Medicine Research 4(6), 1092.

Kanyari, P.W.N., Kagira, J.M. \& Mhoma, J.R., 2009, 'Prevalence and intensity of endoparasites in small ruminants kept by farmers in Kisumu Municipality, Kenya', Livestock Research for Rural Development 21, 111-116.

Commission on Revenue Allocation (CRA), 2013, Kenya: County fact sheet, 2nd edn., CRA, Nairobi.
Khademvatan, S., Hamidreza, M., Hamidreza, K., Negar, A. \& Elham, Y., 2019, 'Prevalence of fasciolosis in livestock and humans: A systematic review and metaanalysis in Iran', Comparative Immunology, Microbiology and Infectious Diseases analysis in Iran', Comparative Immunology, Microbiology and
65, 116-123. https://doi.org/10.1016/j.cimid.2019.05.001

Khanjari, A., Alireza, B., Sepideh, F., Mahboube, B., Abbas, A., Marjan, F. et al., 2014, 'Prevalence of fasciolosis and dicrocoeliosis in slaughtered sheep and goats in Amol Abattoir, Mazandaran, Northern Iran', Asian Pacific Journal of Tropical Diseases 4(2), 120-124. https://doi.org/10.1016/j.cimid.2019.05.001

Khan, M.N., Sajid, M.S., Khan, M.K., Iqbal, Z. \& Hussain, A., 2010, 'Gastrointestinal helminthiasis: Prevalence and associated determinants in domestic ruminants of district Toba Tek Singh, Punjab, Pakistan', Parasitology Research 107, 787-794. https://doi.org/10.1007/s00436-010-1931-x

Kithuka, J.M., Maingi, N., Njeruh, F.M. \& Ombui, J.N., 2002, 'The prevalence and economic importance of bovine fasciolosis in Kenya - an analysis of abattoir data', Onderstepoort Journal of Veterinary Research 69(4), 255-262

Kleiman, F., Pietrokovsky, S., Gil, S. \& Wisnivesky-Colli, C., 2005, 'Comparison of two coprological methods for the veterinary diagnosis of fasciolosis', Arquivo Brasileiro
de Medicina Veterinária e Zootecnia 57(2), 181-185. https://doi.org/10.1590/ de Medicina Veterinária e
S0102-09352005000200007

Legesse, S., Solomon, T., Sewagegn, L., Yohannes, W., Dilip, G. \& Workineh, W., 2017 'Coprological prevalence and associated risk factors of bovine fasciolosis in and around Zenzelma, Bahir Dar, Ethiopia', European Journal of Experimental Biology around Zenzelma, Bahir Dar, Ethiopia', European Journ
7(5), 34. https://doi.org/10.21767/2248-9215.100034

Liu, G., Robin, B.G., Neil, D.Y., Hui-Qun, S., Lin, A. \& Xing-Quan, Z., 2014, 'Complete mitochondrial genomes of the "intermediate form" of Fasciola and Fasciola gigantica, and their comparison with F. hepatica', Parasites \& Vectors 7, 150. https://doi.org/10.1186/1756-3305-7-150

Maciel, M.G., Lima, W.S., Almeida, F.L.M., Arauji, G.A.N., Maciel, L.H.G., Maciel, T.C.S et al., 2018, 'Cross-sectional serological survey of human fascioliasis in Canutam Municipality in Western Amazon, Brazil', Journal of Parasitology Research 2018, 6823638. https://doi.org/10.1155/2018/6823638

Mas-Coma, S., 2004, 'Human Fascoliasis: Epidemiological patterns in Human endemic areas of South America, Africa and Asia', Southeast Asian Journal of Tropical Medicine \& Public Health 35(Suppl 1)

Mas-Coma, S., Valero, M.A. \& Bargues, M.D., 2009, 'Fasciola, lymnaeids and human fascioliasis, with a global overview on disease transmission, epidemiology, fascioliasis, with a global overview on disease transmission, epidemiology, evolutionary genetics, molecular epidemiology and control, Advances
Parasitology 69, 41-146. https://doi.org/10.1016/S0065-308X(09)69002-3

Meerkhan, A.A., Razak, A.H. \& Younis, B.M., 2013, 'The differences between Direct examination and enzyme linked immunosorbent assay (ELISA) test, during the Kurdistan Region of Iraq', International Journal of Chemistry \& Environmemtal Kurdistan Region of Iraq', Internation
Biological Sciences 1(5), 707-709.

Mungube, E.O., Sila, D.M., Kariuki, C.W., Bauni, S.M., Tenhagen, B.A., Wamae, L. et al., 2012, 'A cross-sectional survey on fasciolosis in selected settlements of Taveta Division, Coast province, Kenya', Livestock Research for Rural Development 24, 58 , viewed 22 April 2021, from http://www.Irrd.org//rrd24/4/mung24058.htm.

Nguyen, T.B.N., Nguyen, V.D., Thi, K.L.N., Huynh, H.Q., Huong, T.T.D., Takeshi, A. et al., 2018 , 'Distribution status of hybrid types in large liver flukes, Fasciola species (Digenea: Fasciolidae), from ruminants and humans in Vietnam', Korean Journal of Parasitology 56(5), 453-461.

Rabia, I., Sabry, H. \& Nagy, F., 2010, 'Comparison between different immunological techniques for detection of circulating fasciola antigen in sheep', New York Science Journal 3(7).

Rehman, T., Khan, M.N., Abbas, R.Z., Babar, W., Sikandar, A. \& Zaman, M.A., 2016, 'Serological and coprological analyses for the diagnosis of Fasciola gigantica
infections in bovine hosts from Sargodha, Pakistan', Journal of Helminthology infections in bovine hosts from Sargodha, Pakistan', Journal
90(4), 494-502. https://doi.org/10.1017/S0022149X15000711

Relf, V., Good, B., Hanrahan, J., McCarthy, E., Forbes, A. \& DeWaal, T., 2011, 'Temporal studies on Fasciola hepatica in Galba truncatula in the west of Ireland', Veterinary Studies on Fasciola hepatica in Galba truncatula in the west of Ireland, Veterinary
Parasitology 175(3-4), 287-292. https://doi.org/10.1016/j.vetpar.2010.10.010

Rinaldi, L., Gonzalez, S., Guerrero, J., Aguilera, L.C., Musella, V., Genchi, C. \& Cringoli, G., 2012, 'A one-health integrated approach to control fascioliasis in the Cajamarca valley of Peru', Geospatial Health 6(3), S67-S73.

Shahzad, W., Mehmood, K., Munir, R., Aslam, W., ljaz, M., Ahmad, R., et al., 2012 'Prevalence and molecular diagnosis of Fasciola hepatica in sheep and goats in different Districts of Punjab, Pakistan', Pakistan Veterinary Journal 32(4), 535-538.

Solomon, W. \& Abebe, W., 2007, 'Effects of a strategy antehelmtic treatment intervention of bovine fasciolosis: A conducted in facilities in endemic area in North West Ethiopia', Veterinary Journal 11(3), 59-68.

Theodoropoulos, G., 2011, 'Risk factors and geospatial modelling for the presence of Fasciola hepatica infection in sheep and goat farms in the Greek temperate Mediterranean environment', Parasitology 138(7), 926-938. https://doi. Mediterranean environment', $P$ (10
org/10.1017/S0031182011000436

Tilahun, Z., Nemomsa, D., Himanot, H. \& Girma, K., 2014, 'Study on prevalence of bovine fasciolosis at Nekemte Veterinary clinic, East Wolega Zone, Oromia, Ethiopia', European Journal of Biological Sciences 6(2), 40-45.

Tolan, R.W., 2011, 'Fascioliasis due to Fasciola hepatica and Fasciola gigantica infection: An update on this "neglected" neglected tropical disease', Labmedicine 42(2), 107-116. https://doi.org/10.1309/LMLFBB8PW4SAOYJI

Usip, L.P.E., Ibanga, E.S., Edoho, H.J., Amadi, E.C. \& Utah, E., 2014, 'Prevalence of fascioliasis and the economic loss of condemned liver due to Fasciola infection in cattle slaughtered at three abattoirs in Eket Urban, Akwa Ibom State of Nigeria' Global Advanced Research Journal of Food Science and Technology 3, 054-075.

Waruiru, R.M., Kyvsgaard, N.C., Thamsborg, S.M., Nansen, P., Bøgh, H.O., Munyua, W.K. et al., 2000, 'The prevalence and intensity of helminth and coccidial
infections in dairy cattle in central Kenya', Veterinary Research Communications 24, 39-53. https://doi.org/10.1023/A:1006325405239 